\title{
PERANCANGAN SISTEM APLIKASI INVENTORY BARANG PADA TOKO ABC BERBASIS JAVA STANDARD EDITION
}

\author{
Nasrulloh Isnain ${ }^{1)}$, Rahmatika ${ }^{2)}$, Ahmad Husain ${ }^{3)}$ \\ ${ }^{1}$ Informatika, Teknik dan Ilmu Komputer, Universitas Indraprasta PGRI \\ ${ }^{2}$ Informatika, Teknik dan Ilmu Komputer, Universitas Indraprasta PGRI \\ ${ }^{3}$ Informatika, Teknik dan Ilmu Komputer, Universitas Indraprasta PGRI

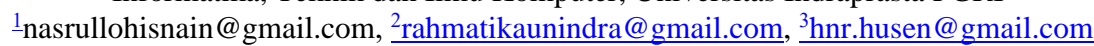

\begin{abstract}
Toko ABC is a business engaged in the sale of furniture which is advanced and growing rapidly in Jakarta. One of the needs for inventory to be implemented properly is to know with certainty the cost of goods sold. In distributing goods to customers, errors often occur in recording and releasing goods, because the current system still uses conventional recording. Therefore, to avoid these problems, a computerized system is applied and in the form of a standard edition java application that handles the inventory.
\end{abstract}

Keywords: Java Standart Edition, Inventory, sale of forniture

\begin{abstract}
Abstrak
Toko ABC adalah sebuah usaha yang bergerak dibidang penjualan furniture yang maju dan berkembang pesat di Jakarta. Salah satu perlunya inventory dilaksanakan dengan baik yaitu mengetahui secara pasti harga pokok dari barang-barang dagangan yang terjual, Dalam melakukan pendistribusian barang kepada pelanggan sering terjadi kesalahan dalam pencatatan dan pengeluaran barang, dikarenakan sistem yang ada pada saat ini masih menggunakan pencatatan secara konvensional. Oleh karena itu, untuk menghindari permasalahan tersebut makan diterapkan sistem terkomputerisasi dan dalam berntuk aplikasi java standart edition yang menangani inventory tersebut.
\end{abstract}

Kata kunci: Java Standart Edition, Inventory, penjualan forniture.

\section{Pendahuluan}

Saat ini kehidupan manusia tidak terlepas dari perkembangan teknologi informasi yang semakin meningkat [9]. Salah satu contoh nyata dan tidak dapat dipungkiri lagi bahwa perkembangan teknologi seperti komputer, saat ini mempunyai peranan yang sangat penting dalam berbagai bidang, salah satunya yaitu dalam bidang penjualan [8].

Toko ABC adalah sebuah usaha yang bergerak dibidang penjualan furniture yang maju dan berkembang pesat di Jakarta. Salah satu perlunya inventory dilaksanakan dengan baik yaitu mengetahui secara pasti harga pokok dari barang-barang dagangan yang terjual. Di samping itu untuk menjamin lancarnya proses inventory barang maka perlu diadakan pencatatan terhadap segala penerimaan barang yang berasal dari supplier, barang yang dipesan oleh pelanggan, barang yang terjual, barang yang dikembalikan oleh pelanggan dan penyesuaianpenyesuaian (adjusment) terhadap barang [1].

\section{a. Sistem Informasi}

Sistem informasi adalah cara yang terorganisir untuk mengumpulkan, memasukkan, dan memproses data dan menyimpannya, mengelola, mengontrol dan melaporkannya sehingga dapat mendukung perusahaan atau organisasi untuk mencapai tujuan [2].

b. Basis Data

Basis Data adakah sekumpulan data yang saling berelasi. Data sendiri merupakan fakta mengenai obyek, orang dan lain-lain. Data dinyatakan dengan nilai (Angka, deret karakter atau Simbol) [3].

c. SQL

Structured Query Language (SQL) adalah sistem manajemen database relasional (RDBMS) yang dirancang untuk aplikasi dengan arsitektur client/server. Istilah client, server, dan client/server dapat digunakan untuk merujuk kepada konsep yang sangat umum atau hal yang spesifik dari perangkat keras atau perangkat lunak [4].

d. Java Standart Edition

Java Platform Standard Edition atau yang dapat disingkat menjadi Java SE merupakan suatu platform yang banyak digunakan untuk pemograman dalam bahasa Java itu sendiri. Java Platform tersebut digunakan untuk menjalankan program yang sebelumnya telah dibuat melalui penggunaan JDK atau Java Development Kit. Java Platform tersebut bisa di bayangkan sebagai virtual machine tempat program Java berjalan sekumpulan library atau package yang dibuktikan [5].

e. Diagram Alir Data

Diagram alir data adalah suatu diagram yang menggambarkan aliran data dari sebuah proses atau sistem. DFD juga menyediakan informasi mengenai luaran dan masukan dari setiap entitas dan proses itu sendiri. DFD tidak memiliki kontrol terhadap alirannya, tidak ada aturan mengenai keputusan maupun pengulangan [7].

f. Java 
Java adalah bahasa pemrograman dan platform komputasi yang pertama kali dirilis oleh Sun Microsystems pada tahun 1995. Ada banyak aplikasi dan situs yang tidak akan bekerja jika tidak ada perangkat lunak Java pada komputer kita. Java itu cepat, aman, dan handal. Dari laptop untuk pusat data, konsol game untuk superkomputer ilmiah, ponsel ke internet, Java ada di mana-mana [10].

\section{Metode Penelitian}

\section{Metode Pustaka}

Yakni metode pengumpulan data dengan cara mempelajari beberapa buku, sarana perpustakaan, dan catatan-catatan yang berhubungan dengan judul yang diajukan..

\section{Metode Survey}

Metode ini digunakan untuk mengetahui dan mempelajari cara kerja dari Sistem Inventory Barang.

Pengumpulan informasi menggunakan :

1. Wawancara (Interview)

Wawancara (interview) yaitu suatu model data dengan mengajukan pertanyaan-pertanyaan atau tanya jawab seputar permasalahan-permasalahan atau kendala-kendala proses dalam melakukan pendistribusian barang kepada pelanggan secara langsung ke pegawai toko $\mathrm{ABC}$ tersebut.

\section{Observasi}

Metode observasi atau pengamatan merupakan salah satu metode pengumpulan data atau fakta yang cukup efektif. Observasi merupakan pengamatan langsung yaitu suatu kegiatan yang bertujuan untuk memperoleh informasi yang diperlukan dengan cara melakukan pengamatan dan pencatatan dengan peninjauan langsung ke toko $\mathrm{ABC}$.

3. Analisis

Analisis digunakan untuk memahami dan menyelidiki secara terperinci aktivitas - aktivitas yang berjalan di toko ABC dengan mengamati kelemahan yang ada selama ini dan mencoba mencari pemecahan masalahnya [6].

\section{Hasil dan Pembahasan}

\section{A. Diagram Aliran Data (DAD) Konteks, Nol dan Rinci}

1. Diagram Konteks

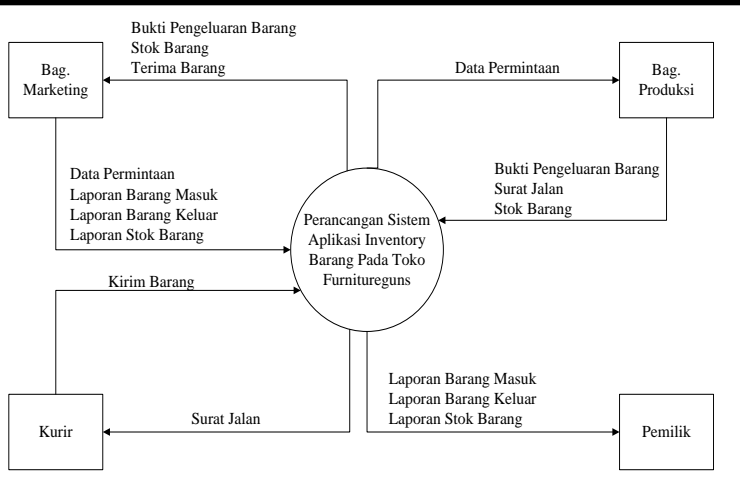

Gambar 1 Diagram Konteks Sistem

\section{Diagram Nol}

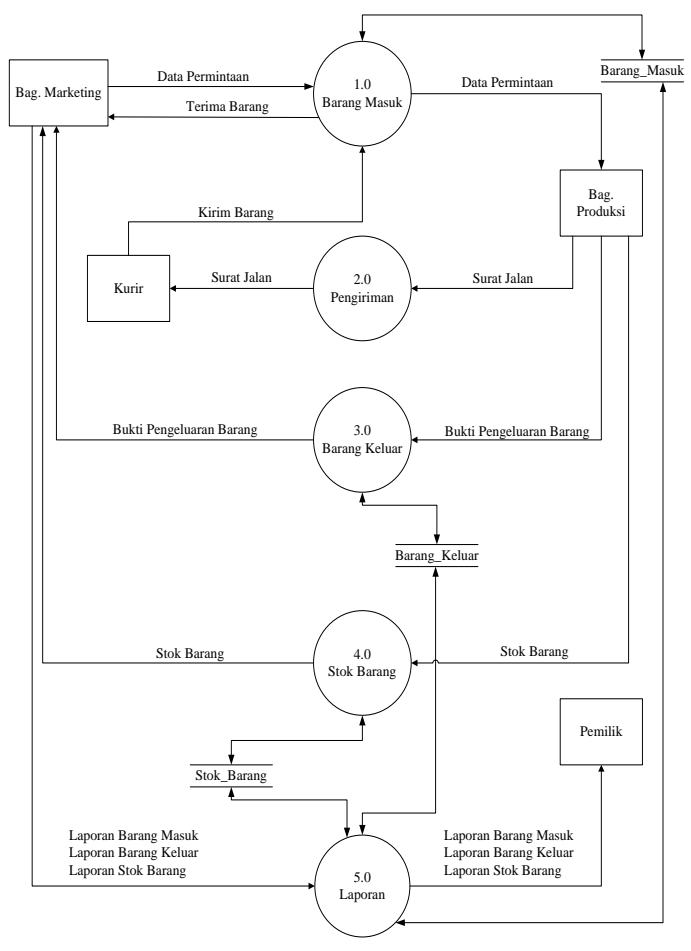

Gambar 2 Diagram Nol Sistem

3. Diagram Rinci Level 1 Untuk Proses

Barang Masuk

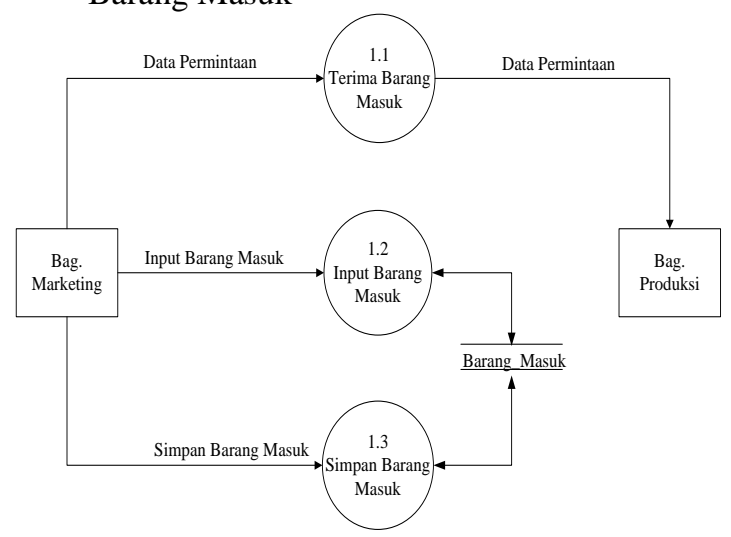

Gambar 3 Diagram Rinci Proses Barang Masuk 
4. Diagram Rinci Level 1 Untuk Proses Pengiriman

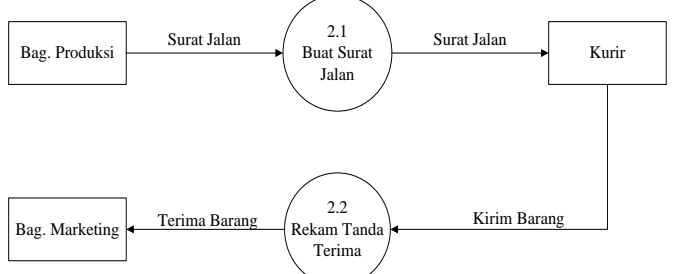

Gambar 4 Diagram Rinci Proses Pengiriman

5. Diagram Rinci Level 1 Untuk Proses Barang Keluar

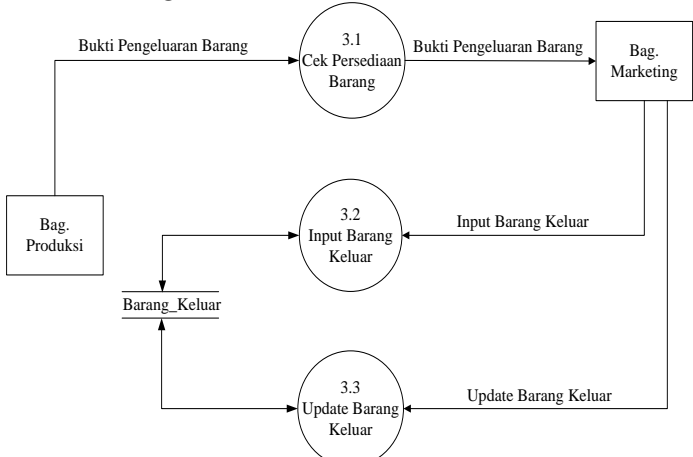

Gambar 5 Diagram Rinci Proses Barang Keluar

6. Diagram Rinci Level 1 Untuk Proses Stok Barang

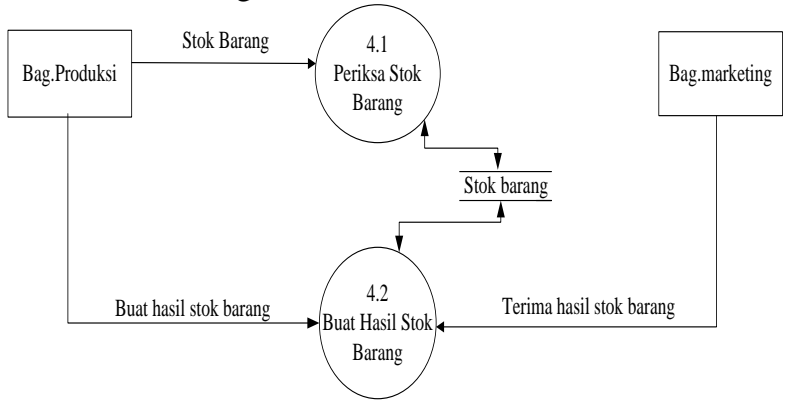

Gambar 6 Diagram Rinci Proses Stok Barang

7. Diagram Rinci Level 1 Untuk Proses Laporan

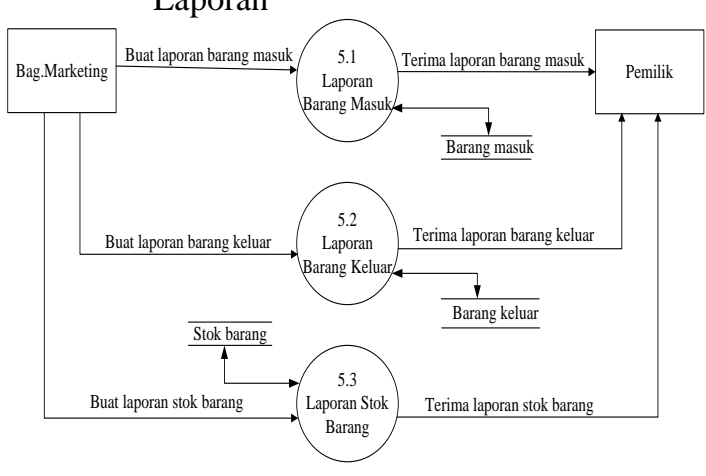

Gambar 7 Diagram Rinci Proses Laporan

\section{B. Rancangan Layar, Rancangan Masukan dan Rancangan Keluara}

1. Menu Login

Pada menu ini menampilkan halaman login pengguna.

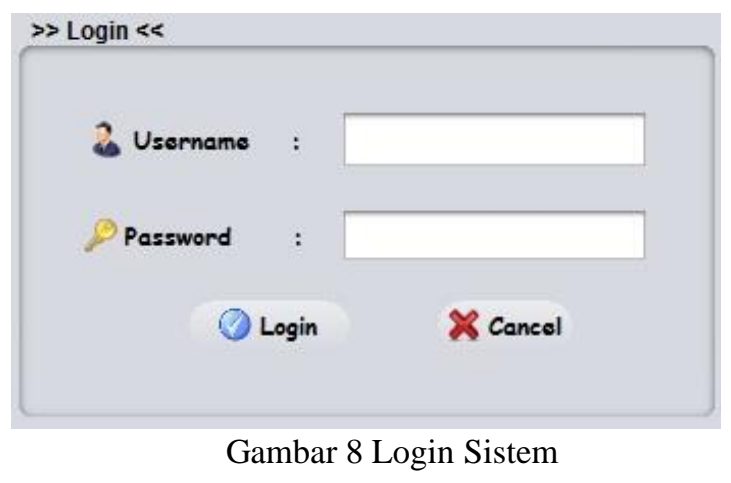

2. Menu Utama

Menu ini menampilkan halaman utama atau dashboard.

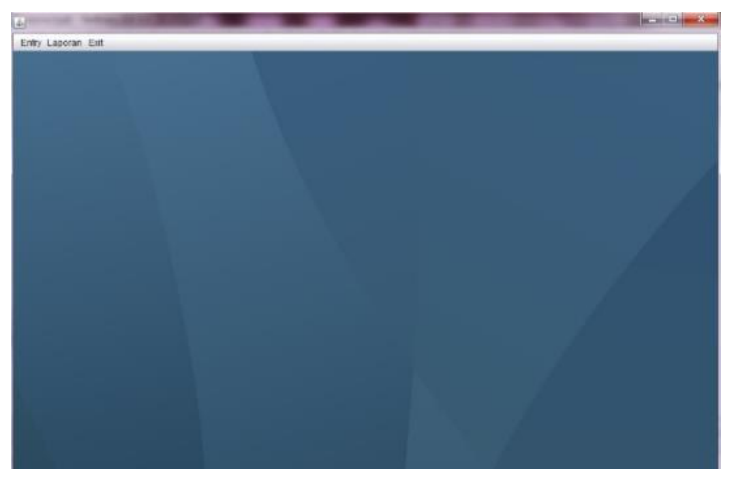

Gambar 9 Rancangan Menu Utama

\section{Barang masuk}

Pada menu ini menampilkan data barang masuk dan input barang masuk.

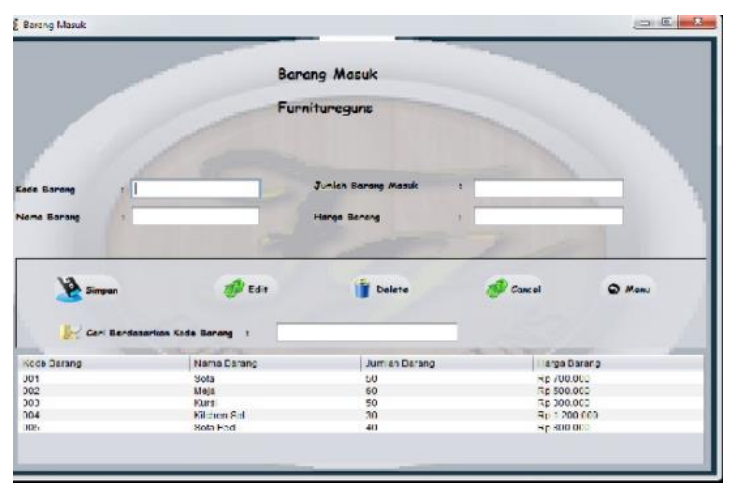

Gambar 10 Rancangan Form Barang Masuk 


\section{Pengeluaran Barang}

Pada menu ini menampilkan data pengeluaran barang dan input data pengeluaran barang.

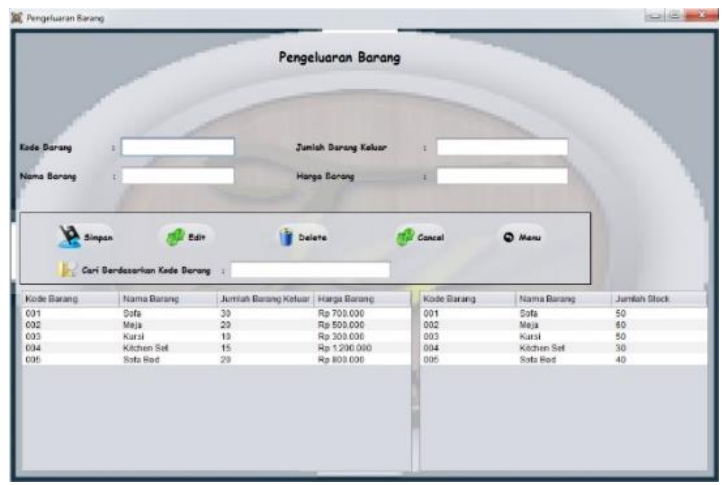

Gambar 11 Rancangan Form barang Keluar

\section{Stok Barang}

Pada menu ini menampilkan data stok barang dan input stok barang.

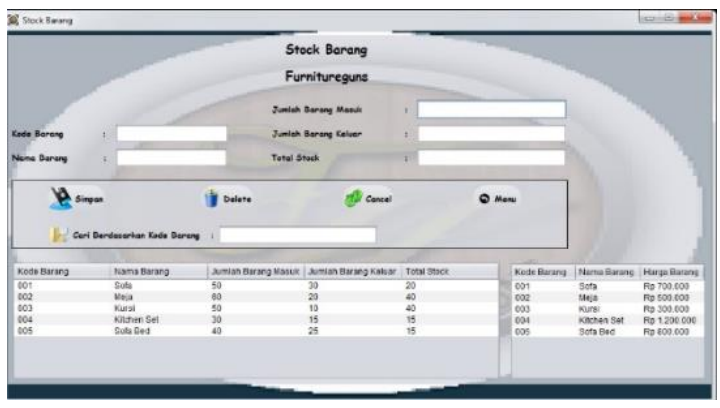

Gambar 12 Rancangan Form Stok Barang

\section{Kesimpulan}

Dengan adanya jasa komputer sebagai alat bantu, penulis mempunyai kesimpulan dengan menggunakan sistem ini berdasarkan perumusahan masalah sebagai berikut :

1. Rancangan aplikasi Inventory Barang pada Toko ABC lebih efektif, cepat, terkonsep dan up to date dalam pengolahan datanya.

2. Uji coba terhadap perancangan aplikasi Inventory Barang pada Toko ABC masih dalam proses pelatihan.

Dengan diterapkannya aplikasi Inventory Barang pada Toko ABC merupakan salah satu langkah maju dalam penerapan teknologi informasi. Inventory Barang yang penulis buat juga sebagai penunjang proses Inventory Barang untuk mengefisienkan waktu dan keamanan data yang setidaknya dapat membantu di dalam inventory barang kepada Toko ABC.

\section{Daftar Rujukan}

[1] Eri, M., Nur, R., Hendra, K., Dwi, S. P, Yanuardi. 2019. Membuat Aplikasi Inventory dengan Java Netbeans, Mysql, dan iReport. Jakarta : Elex Media Komputindo.

[2] Rudi, T. 2012. Manajemen Proyek Sistem Informasi. Yogyakarta : Andi.

[3] Kusrini. 2007. Strategi Perancangan dan Pengelolaan Basis Data, Yogyakarta : Andi.

[4] Helmy, Ridwan, S. 2008. Pengolahan database SQL Server 200 dengan Java 2, Jakarta : Elex Media Komputindo.

[5] Alexandre, B. 2007. Java 6 Java Standard Edition (JSE), Editions ENI.

[6] Ade D.M. 2014. Metode Penelitian Teknik Informatika, Jakarta : Deepublish.

[7] Sindhunata. 2005. Manajemen Sistem Informasi, Jakarta : Gramedia Pustaka Utama.

[8] Hendry, S.T. 2010. Inventri dan Penjualan Terintegrasi, Jakarta : Elex Media Komputindo.

[9] Hendra. A., 2017. Sistem Informasi Inventori Gudang Untuk Mengontrol Persediaan Barang Pada Gudang Studi Kasus : PT.Alaisys Sidoarjo. Journal Of Information Engineering and education Technology, Vol 1. No. 1, E-ISSN 2549-869X

[10] Sigit W, Aloysius., 2010. 7 Proyek aplikasi dengan Java. Elex Media Komputindo, Jakarta 